\title{
CONSIDERAÇÕES PSICANALÍTICAS SOBRE OS JOGOS DE ESCONDER: DO PUTI AO ESCONDE-ESCONDE
}

Humberto Moacir de Oliveira e Jacques Fux

\author{
Humberto Moacir \\ de Oliveira \\ Professor da \\ Faculdade Pitágoras \\ de Ipatinga; mestre \\ em Psicologia \\ pela UFMG; \\ coordenador do \\ CEPP (Centro de \\ Estudo e Pesquisa \\ em Psicanálise do \\ Vale do Aço). \\ Jacques Fux \\ Pós-doutorando em \\ Teoria Literária pelo \\ Instituto de Estudos \\ da Linguagem da \\ Unicamp; doutor \\ em Literatura \\ Comparada na \\ UFMG (POS-LIT, \\ 2010) em cotutela \\ com a Universidade \\ de Lille 3 (2010). \\ Autor do livro: \\ Literatura e matemática: \\ Jorge Luis Borges, \\ Georges Perec e 0 \\ OULIPO (Tradição \\ Planalto, 2011).
}

RESUMO: A psicanálise muito tem discutido sobre a brincadeira infantil, mas pouco tem relacionado as descobertas sobre os jogos de esconder realizadas por Freud a partir de 1920 à teoria de que toda brincadeira representa o desejo de ser adulto. Por meio do estudo das brincadeiras de esconder, o presente trabalho visa revelar como a repetição encontra um lugar na teoria psicanalítica do brincar, tornando-se um operador mais importante do que o próprio desejo de ser adulto, tão caro ao olhar inicial de Freud para as atividades infantis.

Palavras-chave: Brincadeira; esconde-esconde; fantasia, repetição; psicanálise.

ABSTRACT: Psychoanalytic considerations on hide-and-seek games: from Puti to Peekaboo. Psychoanalysis has much discussed children games, but has seldom related the discoveries about hiding and seeking games, carried by Freud in the 1920's, with the theory that all games represent the desire to be an adult. By studying the game of hide-and-seek, the present work aims at revealing how repetition finds its own place in the psychoanalytical theory of play and becomes a much more important operator than the desire a child holds of being an adult, as proposed by Freud.

Keywords: Hiding and seeking games; peekaboo; fantasy, repetition; psychoanalysis. 


\section{INTRODUÇÃO}

A partir de 1920, não por acaso, as brincadeiras de esconder passam a chamar a atenção dos psicanalistas. Entre elas, o jogo de ocultar e revelar o rosto encontra-se fortemente enraizado em nossa cultura. Observando essa brincadeira com mais atenção, percebemos que sua versão brasileira vem quase sempre acompanhada de sons bastante breves como os que Freud (1920/1996) observou na brincadeira de seu neto. Na ocasião, a criança observada emitia sons que lembravam as palavras alemãs fort e da à medida que lançava seu carretel para longe de sua vista (fort: ir) e o puxava de volta (da: aqui). No Brasil, a brincadeira é com frequência acompanhada pelas palavras sumiu e achou ou, em muitos casos, por puti, o que justifica ela ser chamada, em algumas regiões, de jogo do puti.

Além dos já citados jogos, muitas outras variações das brincadeiras de esconder são possíveis. Entre elas podemos citar alguns diferentes formatos da brincadeira do puti, como, por exemplo, o jogo em que, ao invés de se esconder, o adulto esconde a criança com algum pedaço de pano ou objeto similar. Ou ainda, a versão um pouco mais elaborada do mesmo jogo em que é a própria criança que se esconde e aguarda ser descoberta. Em crianças mais maduras, que em geral já não participam dos jogos do puti, e que talvez também já não retiram prazer dos jogos como o do carretel, encontramos ainda a brincadeira em que um grupo se esconde de uma criança a fim de disputar quem fica mais tempo escondido (o único que designaremos aqui por esconde-esconde). Outros jogos poderiam ser citados, mas nos deteremos nessa pequena lista que acreditamos formar um recorte geral dos jogos de esconder presentes no desenvolvimento de quase toda criança. A pergunta que fica é: como essas brincadeiras se relacionam e como podem ser assimiladas pela teoria psicanalítica do brincar?

\section{SOBRE OS JOGOS}

Antes de fazermos alguns avanços teóricos, comecemos analisando esse grande conjunto de brincadeiras que pode ser dividido em alguns subconjuntos. A primeira divisão que podemos fazer é separar duas classes de jogos que se distinguem pela maior atividade ou passividade na brincadeira. Ou seja, teríamos as brincadeiras em que as crianças ou os objetos são escondidos por um adulto e aquelas em que é a criança que se esconde ou esconde o objeto. Na primeira classe de brincadeiras — as brincadeiras passivas — temos dois formatos do jogo do puti: o jogo em que o adulto se esconde e o jogo em que o adulto esconde a criança. Em ambos, quem exerce a função de esconder é o adulto. No outro formato da brincadeira, aquele em que a própria criança se esconde, assim como no jogo do fort da e no jogo do esconde-esconde, é a criança que se oculta ou oculta o objeto. 
Outra distinção que parece ser relevante, mas que talvez só possa ser apreciada teoricamente depois de avançarmos nossa investigação, é a separação entre as brincadeiras em que a criança anseia pelo encontro do objeto escondido e aquelas, ou aquela, em que a criança anseia por sua não revelação. Curiosamente, a maioria das brincadeiras, exceto talvez a última referida, o esconde-esconde, se enquadram dentre as brincadeiras em que a criança anseia por encontrar o objeto ou, no caso de ser ela mesma o objeto escondido, em ser encontrada por um adulto. Mesmo nas brincadeiras em que a criança age ativamente se escondendo ou escondendo o objeto, o desejo de descobrir ou ser descoberto parece estar mais evidente do que o desejo de enganar ou de permanecer escondido, haja vista as crianças não se incomodarem muito com o fato de os adultos notarem onde e como elas estão escondendo o objeto, ou se escondendo.

Nesse momento será bem-vinda uma breve citação que aponta para a confirmação da teoria de que um dos principais operadores do jogo de esconder, mesmo naqueles em que a criança exerce o papel mais ativo, é o desejo de descobrir o objeto ou de ser descoberto por ele. Trata-se de uma citação do escritor francês Georges Perec que, através dos usos curiosos que faz de sua língua, como inserir palíndromos e anagramas em seus textos ou mesmo escrever um livro inteiro sem a letra "e", letra tão fundamental para o francês, diz situar sua escrita na curiosa posição da criança que brinca de esconde-esconde: "Uma vez mais, fui como uma criança que brinca de esconde-esconde e não sabe o que mais teme ou deseja: permanecer escondida, ser descoberta" (PEREC, 1995, p.14).

É muito interessante para o nosso debate a observação do escritor, pois se é a própria criança quem se esconde poderíamos supor que seu maior desejo fosse não ser encontrada ou ao menos ludibriar o outro durante o máximo de tempo possível. Em alguns casos pode até ser que esse desejo de ludibriar se confirme, mas o escritor indica que esse desejo de não ser encontrado divide espaço com outro desejo, o de ser descoberto, ou com um temor, o de não ser descoberto. Em outras palavras, poderíamos dizer que na maioria dos jogos que propomos pesquisar, exceto talvez no que chamamos de esconde-esconde (ainda que nossa definição não coincida totalmente com a de Perec), a criança, mesmo que ativamente escondida, apresenta um claro desejo de ser descoberto que só pode ser fruto, como indica o escritor, de um temor, o temor de não ser encontrado.

Uma última divisão que poderíamos vislumbrar entre as brincadeiras de esconder é a divisão por fases do desenvolvimento. Por achar um tanto quanto precipitado estabelecer uma divisão rígida das idades típicas de cada uma dessas brincadeiras, faremos uma divisão geral e maleável apenas indicando que a tendência geral, nem sempre obedecida, é de as brincadeiras se desenvolverem de acordo com a sequência em que as dispomos no início do texto de forma proposital, ou seja, as brincadeiras do puti parecem ser mais típicas de uma idade 
mais precoce do que a brincadeira do fort da, que por sua vez parece ser mais precoce do que a última das brincadeiras propostas, o esconde-esconde.

Apresentado o material que deverá ser analisado, é hora de passarmos para as considerações teóricas que podemos tecer e assim vermos se as divisões que propomos encontram alguma utilidade para a visão psicanalítica do brincar em geral, e sobretudo, como é o objetivo desse trabalho, elucidar a função que a brincadeira de esconder exerce no ser humano e em sua constituição como sujeito, caminho aberto por Freud em 1920, mas que talvez ainda tenha campos a serem explorados.

\section{O BRINCAR COMO FANTASIA}

Freud se ocupa da função do brincar em vários momentos de sua obra, quase sempre colocando essa atividade tipicamente infantil ao lado da criação artística, tipicamente adulta. Em “Escritores criativos e devaneios”, texto de 1908, o autor afirma que: "O escritor criativo faz o mesmo que a criança que brinca. Cria um mundo de fantasia que ele leva muito a sério, isto é, no qual investe uma grande quantidade de emoção, enquanto mantém uma separação nítida entre o mesmo e a realidade" (FREUD, 1908/1996, p.135).

É nesse sentido que Freud defende que a antítese de brincar não é o que é sério, mas aquilo que é realidade. A fórmula freudiana para o brincar parece se ajustar muito bem à maioria das brincadeiras infantis que se ocupam em construir mundos imaginários, situações heroicas, revivências do mundo cotidiano do adulto, entre outras atividades em que um enredo imaginativo está em jogo. Freud (1908/1996) ainda observa que essas brincadeiras têm em comum um único desejo que auxilia a criança em seu desenvolvimento, o desejo de ser adulto. Temos como exemplos dessas atividades, as brincadeiras como as de papai e mamãe, nas quais as crianças exercem a função de um ou de outro membro do par parental, e que em geral detestam fazer o papel dos filhos. Temos também as brincadeiras de casinha, que novamente reconstituem o ambiente familiar. Ou a brincadeira de médico, que além de satisfazer o desejo de ser adulto permite que a criança explore o corpo humano. Poderíamos incluir aqui também algumas brincadeiras esportivas como o futebol, quando as crianças representam o papel de craques do momento.

Essa ideia divulgada em 1908 já havia sido elaborada por Freud em um texto escrito entre 1905 e 1906, mas que só foi publicado depois de sua morte. Em “Personagens psicopáticos no palco”, Freud (1942/1996) afirma que para a plateia de um teatro, participar do jogo dramático funciona como o equivalente de uma brincadeira infantil. Ou seja, não só o artista, mas também o público, faz do jogo artístico um substituto do brincar e usa essas atividades para satisfazer seus 
desejos dentro de limites considerados normais em sua cultura. Consideramos bastante corriqueiro que uma criança de 8 anos se vista de policial e corra atrás de bandidos imaginários, mas um adulto que tivesse o mesmo comportamento, muito provavelmente seria tratado como anormal. Isso não impede que os adultos ditos normais façam atividades tão infantis e extravagantes quanto essa, desde que seja feita em sua própria imaginação, expressa ou em forma de devaneios ou em expressões artísticas. Enfim, em toda essa discussão primordial de Freud, o brincar ocupa a mesma função da arte, sendo sempre anterior a ela, ou ainda, sendo sempre um modelo, quem sabe uma condição, para arte.

Nos textos citados, o que parece ser compartilhado entre a arte e o brincar é a fantasia. Em 1911 — pouco depois, portanto, dos dois textos aqui referidos —, Freud escreve "Formulações sobre os dois princípios de funcionamento mental", no qual destaca um dos elementos básicos de sua teoria, o princípio de prazer. O princípio de prazer, fundamento tanto para o brincar quanto para a atividade artística, é o mecanismo mental que leva o ser humano, desde os períodos mais primordiais de sua existência, a buscar o prazer independentemente da realidade. O maior resquício desse mecanismo se revela nos sonhos, quando ignoramos a realidade e buscamos afastar de nossa mente qualquer evento que desperte desprazer, como acontece na clássica situação em que o dormente sedento alucina que está ingerindo algum líquido.

Porém, visto que um ser vivo que se encontrasse imerso apenas nessa situação de busca intensa de prazer e desprezo da realidade jamais poderia manter-se vivo por muito tempo, o aparelho psíquico teve de tomar outra atitude perante a vida e se guiar não apenas pelo o que é sentido pela mente como prazer, mas também como real. É importante frisar que o real ao qual Freud se refere aqui se distingue do real lacaniano que trataremos adiante: o real como impossível de ser simbolizado. Isso se revela com mais exatidão quando Freud (1911/1996) chama esse mecanismo de "princípio de realidade", o que nos permite doravante substituir no texto de Freud 'real' por 'realidade'. No exemplo do sujeito sedento que sonha beber água, sabemos bem que a não satisfação da água alucinada o faz acordar e buscar alguma alteração objetiva na realidade. Assim, o princípio de prazer incluiria, para se livrar de novos desapontamentos, outro princípio, o princípio de realidade.

A grande contribuição que essa teoria oferece às brincadeiras infantis é justamente no que se refere à fantasia, pois, como observa Freud, nosso aparelho mental apresenta sérias dificuldades em renunciar a um prazer uma vez obtido, e como o princípio de prazer se manifesta com muito mais liberdade quando não articulado ao princípio de realidade, o aparelho mental se apega a essa forma de obtenção de prazer que independe da realidade e a conserva lado a 
lado com as outras funções do organismo psíquico. Assim é que uma parte de nossas atividades de pensamento é liberada do teste de realidade e permanece subordinada apenas ao princípio de prazer. Nas palavras do próprio Freud: "Esta atividade é o fantasiar, que começa já nas brincadeiras infantis e, posteriormente, conservada como devaneio, abandona a dependência de objetos reais" (FREUD, 1911/1996, p.241).

Temos então uma primeira definição do brincar que se sustenta, sobretudo, no princípio do prazer, conservado na fantasia, e em um dos principais desejos infantis, o de ser adulto, o que muito contribui com o desenvolvimento humano. Essa primeira definição de Freud se apoia em textos anteriores a 1920 e como sabemos muitas mudanças houve na obra freudiana a partir desse ano. Além disso, é fácil observar que a posição freudiana até então defendida se sustenta nos jogos imaginativos mais elaborados, mas traz algumas complicações para a análise das brincadeiras que nos dispomos a estudar. Cabe-nos perguntar, então, se Freud, preocupado nesses textos menos em esclarecer a função do brincar comparadas à atividade do artista, não teria buscado na infância algo já elaborado demais, que talvez seja inadequado para ser tomado como a gênese ou o modelo do brincar, já que podem existir estruturas mais arcaicas a ser consideradas.

Nessa perspectiva é que as brincadeiras de esconder parecem estar em posição mais apropriada para o estudo da gênese do brincar e de sua função mais geral do que os jogos de fantasiar analisados por Freud entre 1905 e 1911. Freud parece ter essa percepção e, por isso, avançaremos nos estudos freudianos buscando resgatar dois outros momentos em que o pai da psicanálise estuda o brincar infantil a partir do que ficou conhecido como sua "segunda tópica”.

\section{O BRINCAR COMO REPETIÇÃO}

Em 1920, no texto “Além do princípio do prazer”, Freud (1920/1996) caminha na direção de algum funcionamento mental que não apenas independa, mas que é mesmo mais fundamental e primordial do que o princípio de prazer com sua variação em princípio de realidade. É nesse texto que podemos encontrar a análise freudiana do jogo do fort da já citado aqui. Estamos de volta ao universo das brincadeiras de esconder, nas quais a fantasia não é tão evidente quanto nas brincadeiras comparadas à arte. Se em um primeiro passo a análise de Freud o conduziu a comparar o brincar com a atividade artística, a comparação agora é de ordem muito menos romântica. A comparação que Freud estabelece em 1920 para o brincar não é com o artista nem com o espectador da arte, mas com os chamados 'neuróticos de guerra', que na classificação atual da medicina se encaixam naquilo que ficou conhecido como Transtorno de Estresse Pós-Traumático. 
A ligação das brincadeiras infantis às neuroses de guerra se deve à interpretação freudiana de uma brincadeira de seu neto. Em um primeiro momento, a criança brincava de jogar os mais variados objetos para longe de sua vista ao mesmo tempo em que emitia um vocábulo que se assemelhava ao alemão fort. Certo dia, a criança encontra um carretel que a permite completar a brincadeira e assim não apenas lança o objeto, perdendo-o, como o faz aparecer outra vez puxando o barbante, quando emite um som semelhante à palavra alemã da. A interpretação de Freud é que o menino revivia nesse jogo a saída da mãe, ou seja, a perda de um objeto importante. Considerando que a primeira parte do jogo independia a segunda, ou seja, que houve uma época em que ele apenas fazia propositalmente perder o objeto, Freud supõe que existe nesse jogo algo análogo às neuroses de guerra. Se nas neuroses de guerra o que se repete é a situação traumática da guerra — os sonhos com explosivos, a alucinose com os barulhos de tiros, entre outras lembranças — no jogo da criança o que é repetido é a perda do objeto materno. Pode-se julgar exagerado comparar a ansiedade causada pelo perigo iminente da morte com a perda temporária da mãe. Mas em psicanálise isso se esclarece quando lembramos que, como afirma Freud (1926/1996), um dos primeiros sinais de ansiedade apresentados pelas crianças é o colo de um estranho, ou seja, a perda do objeto materno (ou familiar).

A conclusão a que essa discussão conduzirá Freud nós já conhecemos, é a compulsão à repetição, e, através dela, a Pulsão de Morte. Isso significa que existe uma tendência, no aparelho psíquico, mais primitiva do que o princípio do prazer e que independe dele. Ou seja, mais do que buscar o prazer, nosso aparelho psíquico busca a repetição, ele busca voltar a um estado anterior de coisas, busca repetir o ocorrido. Freud encontra vários exemplos na natureza que indicam uma tendência universal a esse retorno, desde as migrações dos pássaros e a piracema dos peixes até mesmo o destino de todo ser vivo à morte que nada mais é do que o retorno ao inanimado anterior à vida. A compulsão à repetição, não necessariamente contraria o princípio do prazer, pelo contrário, pode muitas vezes servi-lo, já que prazer é a redução da tensão psíquica e a repetição pode conduzir nossa mente a um estado anterior de menor tensão. Essas conclusões fazem Freud dar outros rumos à sua teoria, mas de maneira alguma abandonar o princípio de prazer e de realidade. Ele apenas reconhece que há algo mais fundamental do que eles, e que é nesse algo que podemos buscar alguma elucidação, tanto para os sonhos dos neuróticos de guerra que repetem uma situação de desprazer quanto para a brincadeira da criança que repete a perda do objeto.

Freud reconhece nessas repetições a tendência do organismo a dominar, vincular as energias não vinculadas na mente. Em um linguajar mais lacaniano, que apresenta certa crítica a essa ideia do domínio, seria mais correto dizer que 
a perda do objeto ou o perigo iminente de morte aparece como real demais, algo inassimilável pelos significantes. Esse real resiste em ser simbolizado pela criança por sua rasa imersão no universo simbólico, assim como resiste no neurótico de guerra pela impossibilidade de o ser humano representar o real da própria morte.

Como ressalta Maria Rita de Oliveira Guimarães: “O inassimilável é algo que não passa à representação, ou, dito de outra maneira, não cessa de não se inscrever. Isso importa no contexto da clínica. Não é simplesmente que não se inscreva, mas que sendo o que não cessa de não se inscrever, é causa de novas transcrições” (GUIMARÃES, 2007, p.3).

Isso que não cessa de não se inscrever, Lacan, no livro 11 de seu Seminário, chama, tomando a palavra emprestada de Aristóteles, de tykhé, em contraponto ao automaton, que é o que Lacan designa por "insistência dos signos aos quais nos vemos comandados pelo princípio do prazer” (LACAN, 1964/2008, p.59). Tykhé, portanto, é o encontro do real, e o real é o que vige sempre atrás do automaton. Não que automaton não seja uma repetição, ele o é, mas não está além do princípio do prazer. O que extrapola esse princípio é o encontro do real, do inassimilável, que não deixa nunca de não se inscrever. Na visão crítica de Lacan, é essa falha na inscrição que mais importa quando Freud descreve a repetição em 1920. O que se repete é a não inscrição do real, o inassimilável do trauma.

Se a ausência da mãe é vivida como uma perda do objeto, um encontro com o real, será esse o trauma, a falta, que não cessará de não se inscrever no jogo do carretel. Para Lacan (1964/2008), exercer o papel ativo no desaparecimento do objeto (que representa a mãe) é secundário, o principal da brincadeira do fort da é a superação da divisão do sujeito. Trata-se da clivagem do próprio sujeito, sua castração: “...a automutilação a partir da qual a ordem da significância vai se pôr em perspectiva” (LACAN, 1964/2008, p.66). Assim, o carretel, na análise lacaniana: “...é alguma coisinha do sujeito que se destaca embora ainda sendo bem dele, que ele segura” (LACAN, 1964/2008, p.66). Essa coisinha que se destaca é o que no estudo de Lacan conhecemos como objeto pequeno a.

Retornando ao estudo freudiano, o que percebemos é que, mesmo em sua análise sobre o fort da, Freud não abandona sua primeira definição do brincar e, depois de dizer que “...em suas brincadeiras as crianças repetem tudo o que lhes causou uma grande impressão na vida real...”, afirma que “...é óbvio que todas as suas brincadeiras são influenciadas por um desejo que as domina o tempo todo: o desejo de crescer e poder fazer o que as pessoas crescidas fazem" (FREUD, 1920/1996, p.27). Essa teoria do brincar será mantida por Freud, porém, a ela será acrescentado o mecanismo de compulsão à repetição e vinculação das energias psíquicas.

Vale a pena retomar, nesse ponto, a já referida crítica que Lacan faz a essa afirmação, quando assinala que: “Dizer que se trata simplesmente para o sujeito 
de se instituir numa função de domínio é uma tolice” (LACAN, 1964/2008, 232). A crítica outra vez se sustenta na operação lacaniana que Miller (2005) designa como uma clivagem da repetição, o que a distingue em dois níveis: tykhé e automaton. Dizer que a repetição é puro domínio, é acreditar: “...que tudo o que fosse da ordem do natural, dado no começo, real, passaria ao simbólico, sem deixar resto. O Seminário 11 assinala que a relação da repetição com o objeto não é a de uma simples anulação” (MILLER, 2005, p.167).

A repetição a que Lacan se refere, portanto, vai ao encontro de um real, e o real se relacionará com o trauma, que Lacan transforma no “...conceito freudiano do inassimilável pelo significante” (MILLER, 2005, p.167), e que é o motor da repetição a partir do Seminário 11. Se o trauma é o inassimilável, ele não pode ser dominado, ele sempre deixa um resto, e é esse resto que motiva a repetição. A repetição, por sua vez, nunca dará conta dessa prometida vinculação, o que não significa que nada pode ser transcrito. Nessa perspectiva, a compulsão à repetição aparece na brincadeira infantil tanto enquanto determinada pelo encontro com o real, tykhé, quanto determinada pela insistência dos signos, automaton, princípio do prazer.

Ainda que seja preciso reconhecer a importância da crítica lacaniana, continuar acompanhando o desenvolvimento do pensamento freudiano pode render bons frutos ao presente trabalho. E o que podemos observar nesse sentido é que Freud já antevia em 1920 a convergência da compulsão à repetição e do princípio do prazer na brincadeira infantil; por exemplo, quando afirma que também as experiências agradáveis, como uma história, tenderão a ser repetidas e que: "Nada disso contradiz o princípio de prazer: a repetição, a reexperiência de algo idêntico, é claramente, em si mesma, uma fonte de prazer” (FREUD, 1920/1996, p.46).

Isso dito, percebemos que além do princípio do prazer e do desejo de ser adulto, também a compulsão à repetição torna-se um conceito fundamental para pensarmos a brincadeira infantil ainda que Freud, como observará Lacan em 1964, não tenha retirado desse fato toda sua magnitude. Resumindo, podemos dizer que na brincadeira infantil convergem a compulsão à repetição e o princípio de prazer: “...aqui, a compulsão à repetição e a satisfação instintual que é imediatamente agradável, parecem convergir em associação íntima” (FREUD, 1920/1996, 33).

Chegamos enfim ao texto "Inibições, sintomas e ansiedade", publicado em 1926, depois, portanto, do avanço freudiano rumo ao além do princípio do prazer e da nova topologia da mente, dividida agora em Isso, Eu e Supereu. A importância desse texto é crucial para nosso trabalho uma vez que será aqui que Freud abordará, ainda que de forma breve, a brincadeira do puti que acreditamos ser uma das mais primitivas brincadeiras infantis, e, portanto, mais primitiva do 
que as duas outras classes de brincadeiras estudadas por Freud, as brincadeiras enredadas pela fantasia de ser adulto e a brincadeira do fort da. Nesse momento, Freud de novo não está interessado especificamente na brincadeira, mas sim em um afeto muito caro à psicanálise, a ansiedade (em alemão: angst).

Depois de propor significativa alteração em sua teoria, colocando a ansiedade não mais como uma libido transformada pelo recalque, mas como causa dele, Freud (1926/1996) afirmará que a ansiedade é incorporada na mente por meio de experiências anteriores. A isso Freud acrescenta que não existe uma experiência mais primitiva de intensa ansiedade do que o nascimento, que é, em outros termos, uma experiência de perda, de perda da mãe e do conforto da vida uterina. Mas, se a ansiedade, como irá sugerir Freud, é um sinal do eu perante o perigo, na situação do nascimento não podemos crer que o recém-nascido esteja ciente dos riscos que está correndo, sendo mais razoável dizer que essa primeira experiência de ansiedade é mais experimentada como dor, desprazer psíquico e corporal, do que como sinal de perigo. Percebemos, então, que a situação traumática causa a dor, excesso de energia psíquica desvinculada, e que a ansiedade é ou a expectativa de que o evento traumático ocorra ou sua repetição.

Mas, se a ansiedade aparece toda vez que a criança supõe a repetição da experiência traumática (e as primeiras experiências traumáticas são sempre experiências que lançam o sujeito no desamparo do mundo externo), toda vez que for abandonada por um adulto, ela dará um sinal da antecipação do perigo que acredita correr. A criança, portanto, sempre que abandonada, revive a situação de sair do conforto da presença do objeto e pressente uma insegurança dando sinais de ansiedade. Os perigos estão, assim, relacionados ao desamparo e à perda do objeto, e perda do objeto, em psicanálise, não tem outro nome senão castração. Estamos de novo no ponto em que Lacan (1964/2008) indica que o carretel é uma "coisinha do sujeito que se destaca".

Esse desamparo humano, que se revela na dependência do bebê a seus primeiros objetos, explica os medos mais convencionais das crianças, como ficar sozinha, ficar no escuro ou ser entregue a um estranho - situações que repetem a perda do objeto. Toda essa digressão nos conduz de volta à brincadeira em geral e à brincadeira de esconder em particular. Pois, o que é a brincadeira do esconder, por exemplo, o jogo do puti, senão uma repetição da perda objetal? Podemos então observar que antes de participar da brincadeira do puti, a criança vivia a separação do objeto como uma experiência traumática de abandono e desamparo. Freud (1926/1996) ressalta que como a criança ainda não sabe distinguir a ausência temporária da perda permanente, ela vive cada experiência de separação como uma morte. É preciso então que repetidas experiências de afastamento ocorram para que a criança perceba que a ausência da mãe pode ser acompanhada de seu reaparecimento. As mães parecem se dar conta de parte 
desse processo, uma vez que muito costumeiramente elas consolam seus filhos com palavras do tipo: “Mamãe está aqui, não precisa chorar, etc." Nesse momento, cabe-nos colocar a referência freudiana mais direta à brincadeira do puti: "A mãe encoraja esse conhecimento [o conhecimento de que o desaparecimento não é permanente], que é tão vital para a criança, fazendo aquela brincadeira tão conhecida de esconder dela o rosto com as mãos e depois, para sua alegria, descobri-lo de novo" (FREUD, 1926/1996, p.165).

Para fins de resumo da situação apresentada, podemos retomar as palavras de Freud proferidas algumas páginas antes de sua referência à brincadeira do puti, para depois retomarmos com mais detalhes a investigação dos jogos de esconder:

\footnotetext{
"A ansiedade é a reação original ao desamparo no trauma, sendo reproduzida depois da situação de perigo como um sinal em busca de ajuda. O ego, que experimentou o trauma passivamente, agora o repete ativamente, em versão enfraquecida, na esperança de ser ele próprio capaz de dirigir seu curso. É certo que as crianças se comportam dessa maneira em relação a toda impressão aflitiva que recebem, reproduzindo-a em suas brincadeiras. Ao passarem assim da passividade para a atividade tentam dominar suas experiências psiquicamente." (FREUD, 1926/1996, p.162)
}

\section{O BRINCAR DE ESCONDER: DO PUTI AO ESCONDE-ESCONDE}

Tendo dito já muita coisa sobre o brincar infantil, desde sua relação com a arte e o fantasiar até sua relação com a compulsão à repetição e a ansiedade, chegamos à conclusão de que além de se apoiar na satisfação do princípio do prazer, reservando um pedaço do eu livre das condições do mundo externo (base do conceito freudiano de fantasia), o brincar também serve à criança como uma maneira de satisfazer a compulsão à repetição. Serão esses postulados que nos guiarão na pesquisa sobre o brincar de esconder a que nos propomos, com a única ressalva de que precisaremos extrapolar um pouco a teoria freudiana da vinculação, se quisermos acatar o conselho de Lacan (1964/2008) de que ficar preso ao domínio seria uma tolice.

Comecemos pelo que achamos de mais primitivo em nossas pesquisas. Referimo-nos à experiência da perda objetal. Isso quer dizer que nem sempre a criança pôde participar do jogo de esconder, pois existia uma época em que ela mesma não se distinguia da mãe e a separação não poderia de maneira alguma ser experimentada como uma brincadeira nem a criança poderia dela retirar prazer. Vimos com Lacan (1964/2008), que a brincadeira do carretel, por exemplo, exige uma superação da clivagem do sujeito. Antes de brincar de esconder, a criança tem de ter experimentado a separação da mãe ou do adulto protetor como o avesso do prazer lúdico, um tormento comparável aos traumas 
de guerras ou a outras situações de perigo de vida. É só depois de verificar que o objeto não faz parte do eu infantil, só depois de destacar essa coisinha que será o objeto a, é que ela pode finalmente entrar no jogo e retirar algum prazer. Pois, não duvidemos, um dos principais motivos de toda brincadeira é retirar alguma cota de prazer.

Vencida essa primeira etapa e preparada para a brincadeira, a criança, desde que auxiliada por um adulto, pode então repetir essa experiência traumática em forma de jogo. Temos agora uma bonificação por ter separado em grupos as diversas formas do brincar de esconder, pois podemos relacionar esses grupos e dizer que as brincadeiras mais antigas são as mesmas que, na separação por atividade, ficaram na classe das passivas. A criança então é convidada pelo adulto ao jogo de perder o objeto e retomá-lo, o que talvez seja o primeiro passo rumo à superação da divisão do eu. É importante aqui destacarmos outra vez que a maioria dessas brincadeiras é acompanhada de vocábulos simples que lembram o fort e o da da brincadeira do carretel. Esses vocábulos, como sumiu e achou, puti e outros, devem ter sua função psíquica, uma vez que são, em sua maioria, antítese significante, um S1 e um S2: “Não há fort sem da...” (LACAN, 1964/2008, p.232). Ainda que, como lembra Lacan, não seja da oposição pura e simples do fort e do da que o jogo retira sua força inaugural (mas sim do carretel enquanto objeto a) essa oposição entre os sons emitidos parecem não ser gratuitas, uma vez que colocam o sujeito entre dois significantes que o auxiliarão rumo à superação da castração.

Se assim de fato for, temos então que a primeira função do brincar não é atender ao desejo de ser adulto, mas de tentar inscrever a falta inassimilável do objeto que não cessa de não se inscrever. A criança encontra no convite do adulto à brincadeira de esconder o rosto uma das primeiras tentativas dessa inscrição. Muito provavelmente, as primeiras brincadeiras que se tornam possíveis à criança é a que chamamos de puti, e nelas a criança participa inicialmente de forma passiva, ansiando pelo encontro do objeto que desapareceu por iniciativa do adulto.

A próxima etapa, como já é possível supor, é quando a criança passa a exercer um papel ativo na brincadeira, ou se escondendo do adulto ou escondendo seus objetos. Aqui temos a brincadeira do fort da e a do puti em que a criança se esconde, ambas com um funcionamento muito semelhante ao que encontramos na primeira etapa, mas com a diferença de que é a criança agora que exerce o papel fundamental do jogo. Agora é a criança que começa a operar com os primeiros vocábulos e a colocá-los dentro da operação significante opondo-os de acordo com o momento da brincadeira. Aqui a criança pode simbolizar o objeto através não apenas de antíteses significantes como o puti e o achou, como, principalmente, do carretel e outros objetos. Mesmo nesse momento ainda não temos argumentos muito fortes para dizer que a criança brinca para atender 
seu desejo de ser adulto; o que parece imperar nesse caso ainda é a compulsão à repetição e sua relação com o trauma.

Logicamente não podemos dizer que essas etapas são bem delimitadas e rígidas, mas seguindo nosso raciocínio, apenas um pouco mais tarde é que a criança começaria por encarar o jogo como um desafio e poderia retirar prazer de se esconder de outra criança com a preocupação de não ser encontrada durante muito tempo. Teríamos aqui, por fim, a situação de esconde-esconde. Ainda que não seja óbvia a relação que esse jogo apresenta com o desejo de ser adulto, podemos dizer que é por volta desse período que observamos com mais clareza a presença de brincadeiras que atendam ao desejo de ser adulto. Mesmo o esconde-esconde apresenta uma versão em que um grupo de crianças representando a polícia sai à procura de outras crianças escondidas que representam os bandidos: a brincadeira de polícia e ladrão. Seria o encontro do jogo de esconder com a fantasia de ser adulto?

Essa pergunta, talvez inevitável, de saber quando o jogo da repetição do trauma encontra com o jogo fantasioso de ser adulto, ou se eles sempre coexistiram no desenvolvimento do sujeito, é difícil de responder. Mas a resposta pode ser procurada na relação do sujeito com o objeto, que como aprendemos com Freud (1923/1996), pode ser pelo menos de duas ordens que por vezes convergem: um desejo de ter e um desejo de ser o objeto. Assim, a criança representaria em suas brincadeiras ambas as situações, uma em que ela repete a perda do objeto e outra em que ela, fantasiosamente, se identifica com o objeto amado, que é também uma das formas de ter o objeto. Freud (1923/1996) defenderá essa hipótese afirmando que se o Eu se apresentar ao Isso de modo semelhante ao objeto perdido, o Isso pode amar o objeto através do amor narcísico que sente pelo Eu. Em outras palavras, se uma criança se assemelha ao adulto, ela pode amar essa parte de si que se parece com esse adulto. Assim, é notável os meninos que buscam usar os sapatos dos pais ou as meninas que buscam se maquiar como a mãe. Tudo isso confirma e explica a hipótese de que o brincar se guia pelo desejo de ser adulto.

Teríamos nessa distinção entre o amor do ter e o amor do ser duas formas da criança tentar inscrever o real: repetindo a perda objetal e fantasiando ser adulto. É ainda apenas um esboço de resposta a essa pergunta que permanece em aberto. Por enquanto, apenas sugeriremos que o mesmo motor que move a repetição, aquilo que não cessa de não se inscrever, move também a fantasia presente nos jogos mais elaborados da criança. Como afirma Lacan, “...o real vai do trauma à fantasia...”, já que “...a fantasia nunca é mais do que a tela que dissimula algo de absolutamente primeiro, de determinante na função da repetição” (LACAN, 1964/2008, p.64). Talvez o que possa ser proposto nesse instante é que o real também vai da brincadeira do esconder à brincadeira do fantasiar ser adulto. 


\section{CONSIDERAÇÕES FINAIS}

Embora algumas questões ainda estejam em aberto, a análise das brincadeiras de esconder não parece ter sido em vão. Além de trazermos reflexões para a teoria freudiana do brincar, também pudemos penetrar um pouco mais na função que o esconder exerce na vida do ser humano. O ponto a que chegamos é que o real da falta do objeto é o que sustenta os primeiros jogos de esconder e é o avanço desse movimento que possibilita novas brincadeiras.

Se Éric Laurent (apud GUIMARÃES, 2007) diz que no jogo do fort da a criança simboliza a ausência e a presença, podemos dizer que outros jogos de esconder também cumprem essa função ou ao menos preparam o infante para ela. $\mathrm{O}$ autor ainda diz que a criança não tem a possibilidade de escrever em algum lugar que sua mãe partiu. O jogo de esconder ajuda no desenvolvimento dessa escrita, que se nunca será realizada, não significa que nada pode ser feito. Para Laurent, o carretel que simboliza a ausência e a presença pode ser transformado em urso de pelúcia, que é o que a criança busca quando tem que enfrentar uma separação. As crianças recusam dormir, pois dormir é uma separação, dormir é estar sozinho, o urso as ajuda nesse sentido. O esconder as ajuda a chegar ao urso. E é assim, num jogo de esconde-esconde, de presença e ausência, de puti e achou, de carretel e urso, que a criança tem a chance de "suportar a angústia do nada de traço da presença da ausência” (LAURENT, apud GUIMARÃES, 2007, p.4).

Recebido em 5/3/2012. Aprovado em 30/5/2012.

\section{REFERÊNCIĀS}

FREUD, S. (1996) Edição standard das obras psicológicas completas de Sigmund Freud. Rio de Janeiro: Imago.

(1908) “Escritores criativos e devaneios”, v.IX, p.133-146.

(1911) "Formulações sobre os dois princípios de funcionamento mental”, v.XII, p.233-246.

(1920) “Além do princípio do prazer”, v.XVIII, p.13-78.

(1923) “O Ego e o Id”, v.XIX, p.15-82.

(1926) "Inibições, sintomas e ansiedade”, v.XX, p.81-174.

(1942) "Personagens psicopáticos no palco”, v.VII, p.289-298.

FUX, J. (2011) O ludicamente sério e o seriamente lúdico de Georges Perec. Revista Criação \& Crítica, São Paulo, v.6, p.28-43. Disponível em: $<$ http://www.fflch.usp.br/dlm/criacaoecritica/dmdocuments/ CC_N6_JFux.pdf $>$. Acesso em 10/12/2011. 
GUIMARÃES, M. R. O. (2007) Os três tempos do objeto no Fort-Da. Almanaque On-line, Belo Horizonte, Ano 01, n.1, p.1-6, 2007. Disponível em: < http://www.institutopsicanalise-mg.com.br/psicanalise/ almanaque/textos/Texto\%20M\%201\%20.\%20Rita.revis.\%20-\%20 5\%20laudas\%20-.pdf >. Acesso em 10/12/2011.

LACAN, J. (1964/2008) O Seminário, livro 11: os quatro conceitos fundamentais da psicanálise. Rio de Janeiro: Jorge Zahar.

MILLER, J-A. (2005) Silet. Rio de Janeiro: Jorge Zahar.

PEREC, G. (1995) W ou a memória da infância. São Paulo: Companhia das Letras, 1995.

Humberto Moacir de Oliveira beto7296@yahoo.com.br

Jacques Fux

jacfux@gmail.com 
